\title{
El despido en la reforma de la ley de Fomento del Empleo
}

Carlos Blancas Bustamante

En la extinción de la relación de trabajo, y particularmente en el despido -que constituye el motivo más frecuente de aquélla-, se patentiza la divergencia profunda de intereses entre el trabajador y el empleador.

Como lo anota Martín Valverde ${ }^{1}$, el interés del trabajador se centrará normalmente en la conservación del empleo, interés éste jurídicamente protegido por el derecho al trabajo y a la libre elección de profesión u oficio, reconocido expresamente por la Constitución española. A su vez, el interés del empleador se encamina a la obtención de las mayores facilidades en la contratación y gestión de la mano de obra, encontrando amparo jurídico en la libertad de empresa, igualmente reconocida por la Constitución de España y la mayoría de los ordenamientos jurídicos.

Orientados, respectivamente, por estos intereses, los trabajadores perseguirán una legislación que les otorgue estabilidad en el empleo o, cuando menos, dificulte la extinción del contrato de trabajo por voluntad unilateral del empleador, en tanto que los empleadores buscarán mayores márgenes de autonomía para disponer del factor trabajo, reduciendo al máximo la intervención legal, como los mismos autores lo indican ${ }^{2}$.

De esta suerte, la regulación legal de la extinción de la relación laboral, y especialmente la del despido, constituye una de las materias más importantes y, además, polémicas y controvertidas, de la legislación del trabajo, siendo no pocos los debates que suscita cualquier iniciativa legal que la afecte.

En nuestro país, que desde el año 1970 con la dación del decreto ley 18471 ha tenido un régimen legal de estabilidad en el trabajo -derecho

\footnotetext{
Martin Valverde, Antonio, Rodriguez-Sañudo Gutierrez, Fermín, y Garcia MurCiA. Joaquín, Derecho del trabajo, Editorial Tecnos, Madrid, 1991, p. 533.

Loc. cit.
} 
que alcanzó rango constitucional en el artículo 48 de la Constitución de 1979-, la reciente promulgación de la ley $26513^{3}$, que modifica parcialmente la ley de Fomento del Empleo (LFE) - decreto legislativo 728-y deroga la ley de Estabilidad en el Trabajo (LET) -ley 24514-, ha supuesto una alteración radical de las normas sobre el despido y la estabilidad en el trabajo, que alcanza las bases mismas de un régimen legal que, aun cuando sufrió no pocos cambios, permaneció entre nosotros durante casi un cuarto de siglo.

\section{Evolución conceptual y legislativa del despido}

Para ubicar correctamente el punto en que se ha situado actualmente la legislación peruana sobre la estabilidad laboral y la extinción de la relación laboral mediante el despido, conviene presentar el panorama de la evolución que la regulación de esta materia ha seguido, tanto en el Derecho positivo cuanto en la doctrina jurídica.

$\mathrm{Al}$ respecto, considero que en esta evolución pueden distinguirse tres grandes etapas o momentos, a saber: 1) el despido como un poder patronal absoluto; 2) el despido como un poder limitado, y 3) el despido como un poder excepcional.

\subsection{El despido como poder absoluto}

Corresponde a la etapa inicial de la formación del Derecho del trabajo, cuando los principios e instituciones características de esta disciplina no se encontraban definidos $y$, por tanto, las relaciones de trabajo eran habitualmente reguladas por los códigos civiles, que solían encuadrarlas dentro de la figura contractual del arrendamiento de servicios.

Bajo esa perspectiva, se consideraba que el contrato podía ser resuelto libremente, en cualquier momento, por decisión de cualquiera de las partes. En tal sentido, el empleador disponía del poder de despedir al trabajador libremente, sin que la validez de su decisión estuviera condicionada por exigencias de fondo, de forma o, menos aún, por la obligación de resarcir al trabajador de alguna manera.

Por decreto supremo 05-95-TR, publicado en El Peruano el 18 de agosto de 1995, se aprobó, en cumplimiento de la facultad otorgada al Poder Ejecutivo por la quinta Disposición Transitoria de la ley 26513, el Texto Único Ordenado de la Ley de Fomento del Empleo (TÚOLFE), que unifica y reordena el articulado de la LFE, con los cambios introducidos. 
Esta forma de extinción de la relación de trabajo corresponde a lo que la doctrina suele calificar como despido ad nutum, que "[...] ha de entenderse como un ejercicio del poder empresarial sin limitaciones de ninguna clase. Sin límites causales, de modo que pudiera ser despedido el trabajador en cualquier momento y sin alegación de causa alguna; sin límites formales, de manera que el despido pudiera realizarse sin necesidad de someterse a reglas o normas formales determinadas, y sin límites en los efectos o consecuencias, de suerte que la resolución no arrastrase consigo la obligación empresarial de indemnizarse daños y perjuicios» ${ }^{4}$.

En el despido ad nutum, siendo la facultad de despedir que se reconoce al empleador, absoluta, discrecional e incausada, no se plantea la cuestión de la legitimidad del despido. En efecto, cualquiera que sea el motivo -o aun la ausencia de éste- o la forma utilizada -o aun la omisión de toda forma propiamente dicha-, el despido decidido unilateralmente por el empleador constituye el ejercicio legítimo de una potestad que el ordenamiento jurídico le atribuye, y, por consiguiente, no es susceptible de ser cuestionado en sede judicial ni, tampoco, administrativa.

Dicho en otras palabras, el trabajador despedido carece del derecho de impugnar o reclamar contra el despido, así como del de obtener alguna forma de reparación por los perjuicios que le ocasione el ser privado de su puesto de trabajo.

Este sistema rigió en el Perú hasta la dación de la ley 4916, del 7 de febrero de 1924.

\subsection{El poder limitado para despedir}

El desarrollo del Derecho laboral -con sus principios e instituciones propias, inspiradas en la protección del trabajador como medio para equilibrar la desigualdad real de la relación empleador-trabajador-, aparejó, necesariamente, la limitación del poder empresarial de extinguir unilateralmente la relación de trabajo.

Surgieron así, en efecto, diversa clases de límites que la legislación laboral estableció para dificultar el despido. Estos límites fueron principalmente de dos tipos: formales y económicos.

Los primeros tuvieron su expresión típica en la figura del preaviso, en virtud de la cual se eliminó la posibilidad del despido intempestivo o

\footnotetext{
4 Alonso GarCía, Manuel, Curso de Derecho del Trabajo, Editorial Ariel, Barcelona, 1981, p. 562
} 
súbito, otorgándose al trabajador el derecho de ser notificado, con prudencial antelación, de la decisión empresarial de despedirlo, a fin de que en el lapso que mediaba entre dicha comunicación y su cese efectivo pudiera obtener otra colocación, y, de este modo, evitar el desempleo.

La otra limitación tuvo un contenido esencialmente económico y consistió en reconocer el derecho del trabajador, y la correlativa obligación del empleador, de ser resarcido por la ruptura del vínculo laboral mediante el pago de una indemnización, generalmente tasada.

Refiriéndose a esta clase de limitaciones, $\mathrm{Pla}$, citando una expresión de Martins Catharino, las califica como "limitaciones laborales impropias" y precisa que éstas no niegan el derecho a despedir sino que, por el contrario, "parten del supuesto de que es un derecho patronal"s.

Agrega este mismo autor, que la eficacia de estas limitaciones depende de su onerosidad, siendo ineficaces cuando la indemnización es mínima y operando, en cambio, como un sistema restrictivo, cuando su cuantía es elevada. Concluye, por ello, que: "Se trata, pues, de una limitación elástica, en la que actúan frenos económicos y no jurídicos.» ${ }^{6}$.

Bajo esta regulación, tampoco es posible entrar a juzgar la legitimidad del acto de despido, pues el empleador sigue gozando de una facultad ad libitum para despedir, bien que estando, ahora, obligado ya sea a respetar una formalidad o a resarcir al trabajador, o, a veces, a ambas cosas. El incumplimiento en que incurra el empleador por no respetar tales límites, no afecta la validez ni la eficacia del despido, generando únicamente el derecho del trabajador a obtener la reparación correspondiente a través de un proceso judicial.

Se trata, en definitiva, como lo ha calificado la doctrina, de un «despido pagado", no sujeto a requisitos de fondo en cuanto a la existencia de una causa como elemento legitimador del despido.

Éste es el régimen legal que se instauró en el Perú con la ley 4916 y su reglamento del 22 de junio de 1928. Estas normas introdujeron en el Perú las figuras del preaviso y de la indemnización por despido, como limitaciones iniciales al poder empresarial de despedir al trabajador?

Pla Rodriguez, Américo, Los principios del Derecho del trabajo, Ediciones Depalma, Buenos Aires, 1978, p. 173.

Ibid., p. 174 .

La ley 4916 estableció que el patrón podía dar por terminada la relación laboral dando al trabajador un preaviso de noventa días. El despido «intempestivo", es decir, aquel que omitiera dicho preaviso, daba al trabajador el derecho a percibir los sueldos correspondientes a ese trimestre, conforme al artículo 28 del reglamento de dicha ley. Asimismo, la compensación por tiempo de servicios sólo procedía cuando el patrón despedía al trabajador sin existir causa justificatoria. En caso de que el despido estuviera sustentado en alguna de las causales entonces enumeradas en el artículo 294 del Código de Comercio, el trabajador no tenía derecho al preaviso ni a la indemnización. 
Posteriormente, la compensación por tiempo de servicios se transformó en una indemnización por "antigüedad", siendo procedente su pago en todos los supuestos de extinción de la relación laboral, incluyendo el despido basado en una causa justa, perdiendo su carácter reparador del despido injustificado o arbitrario.

\subsection{El poder excepcional de despedir}

Señala Martín Valverde que: "Característica de la legislación laboral ha sido la progresiva restricción de la facultad empresarial de poner fin a la relación de trabajo, para garantizar la estabilidad en el empleo. Esta tendencia ha afectado sobre todo a la facultad de despido, para la que se exige la concurrencia de causa justa.. ${ }^{8}$.

Pla, por su parte, comparando la nueva situación con la anterior, en que prevalecían las "limitaciones laborales impropias", anota que: "La estabilidad, en cambio, parte del supuesto contrario, o sea, de que el empleador no tiene derecho a despedir sino cuando hay causa justificada." .

En tal virtud, el poder empresarial de despedir al trabajador se transforma en un "poder excepcional" en lugar de ser un poder ordinario. Ello quiere decir que: «No existe dicha facultad salvo en determinadas circunstancias, más o menos excepcionales: el despido está -en principio- prohibido, salvo que concurra una de las causas justas previstas en la ley o en la norma jurídica en cuestión. ${ }^{10}$.

La "causa justa» viene, de este modo, a constituirse en el elemento legitimador del despido: en el supuesto habilitante del poder patronal para despedir. La existencia de la causa justa hace emerger el poder empresarial para el despido y convierte a éste en un acto legítimo. Por el contrario, la ausencia de una causa justa supone que el despido es un acto arbitrario, basado en un poder de hecho pero carente de legitimidad jurídica.

Ello significa que, producido el despido, el trabajador que no lo considere justificado puede impugnar -generalmente en sede judicial- su legitimidad, y llegar a obtener un pronunciamiento judicial que declare ilegítimo aquel acto patronal. Se establece así una diferencia sustancial

MarTin Valverde, Antonio, op. cit., p. 537.

Pla Rodriguez, Américo, op. cit., p. 174.

ERMIDA, Oscar, «La estabilidad laboral en América latina», en Boletín OIT INFORMA, año I, núm. 1, 1989, p. 6. 
con la figura del "despido pagado", en la que sólo es posible exigir la compensación económica del despido.

Es importante señalar que esta evolución hacia el «despido causal" ha alcanzado reconocimiento internacional a través del Convenio 158 de la OIT (Conv. 158 OIT) sobre "La terminación de la relación de trabajo por iniciativa del empleador", cuyo artículo 4 dispone que "no se pondrá término a la relación de trabajo de un empleador a menos que exista para ello una causa justificada». Al respecto se ha señalado, con absoluta nitidez, que: "La necesidad de que la terminación se fundamente en una causa justificada constituye la piedra angular de las disposiciones del Convenio. Al adoptarse este principio, el empleador pierde la facultad de poner término unilateralmente a una relación de trabajo de duración indeterminada mediante la notificación de un preaviso o, en su lugar, el pago de una indemnización.» ${ }^{11}$.

Asimismo, el Protocolo adicional a la Convención Americana sobre Derechos Humanos, en materia de derechos económicos, sociales y culturales (1988), prescribe en su artículo 7 que: los «[...] Estados garantizarán en sus legislaciones nacionales, de manera particular: [...] d) La estabilidad de los trabajadores en sus empleos, de acuerdo con las características de las industrias y profesiones y con las causas de justa separación. En casos de despido injustificado, el trabajador tendrá derecho a una indemnización o a la readmisión en el empleo o a cualesquiera otra prestación prevista por la legislación nacional.»" ${ }^{12}$.

En el Perú, la exigencia de que el despido se fundamente en una causa justa fue introducida por el decreto ley $18471^{13}$, que asimismo estableció, por vez primera, un régimen de estabilidad en el trabajo. Con diversos cambios, retrocesos y perfeccionamientos legislativos, el sistema de estabilidad laboral se mantuvo a través del decreto ley $22126^{14}$, la ley $24514^{15}$ y el decreto legislativo 728 , ley de Fomento del Empleo ${ }^{16}$.

\footnotetext{
11 Conferencia Internacional del Trabajo, 82. ${ }^{\circ}$ reunión, 1995, "Protección contra el despido injustificado", Informe III, (parte 4B), Oficina Internacional del Trabajo, Ginebra, 1995 , p. 37.

12 Este protocolo ha sido ratificado por el Perú mediante resolución legislativa 26448, del 28 de abril de 1995, publicada en el diario oficial El Peruano el 7 de mayo del mismo año.

1.3 Promulgado el 10 de noviembre de 1970 por el Gobierno Revolucionario de la Fuerza Armada.

14 Promulgado por el Gobierno Revolucionario de la Fuerza Armada el 21 de marzo de 1978.

Promulgada por el régimen constitucional 1985-1990, el 4 de junio de 1986.

Dictado por el gobierno constitucional el 8 de noviembre de 1991 , en ejercicio de las facultades legislativas delegadas por el Congreso mediante la ley 25327.
} 
Es relevante señalar que la Constitución de 1978 elevó a la categoría de derecho fundamental la estabilidad en el trabajo, al establecer en su artículo 48 que: «El Estado reconoce el derecho de estabilidad en el trabajo. El trabajador sólo puede ser despedido por causa justa, señalada en la ley y debidamente comprobada."

Esta norma fue sustituida, al derogarse la Constitución de 1979 -a consecuencia de la ruptura del orden constitucional el 5 de abril de 1992-, por el artículo 27 de la Constitución de 1993, que suprime toda referencia a la estabilidad en el trabajo y se limita a señalar que: "La ley otorga al trabajador adecuada protección contra el despido arbitrario."

\section{El despido arbitrario en la ley de Fomento del Empleo}

La ley 26513 modifica la LFE y deroga la LET, con el objeto de establecer una nueva normativa sobre el despido, dentro del amplio margen que concede al legislador la genérica redacción del artículo 27 de la nueva Constitución.

En efecto, al dictarse la LFE, que fue la primera expresión de una normativa dirigida a debilitar la regulación legal de la estabilidad laboral y el despido, se encontraba vigente la Constitución de 1979, cuyo artículo 48 se caracterizó por definir con precisión el derecho a la estabilidad en el trabajo. Consiguientemente, la LFE -más allá de las intenciones de sus inspiradores y autores- hubo de mantenerse dentro de ese marco constitucional, para no incurrir en vicio de inconstitucionalidad.

Liberado de ese marco, el legislador ha podido ahora acometer, sin mayor dificultad, la tarea de desregular esta materia, y ése ha sido el origen y la finalidad de la reforma de la LFE por la ley 26513, que ha dado lugar al vigente Texto Único Ordenado de la LFE (TÚOLFE).

\subsection{El despido causal en el TÚOLFE}

A primera vista, el TÚOLFE se mantiene dentro de la corriente que hace de la existencia de una causa justa la condición sine qua non para la validez jurídica del despido.

En efecto, el artículo 55 TÚOLFE señala que para el despido de un trabajador sujeto a régimen de la actividad privada, que labore cuatro o más horas diarias para un mismo empleador, «es indispensable la existencia de causa justa contemplada en la ley y debidamente comprobada". A su vez, los artículos 56,57 y 58 enumeran taxativamente las 
causas justas de despido relacionadas, respectivamente, con la capacidad y la conducta del trabajador.

En la misma línea -la de concebir al despido como un acto causal-, el artículo 64 regula el procedimiento previo al despido, que obliga al empleador a comunicar al trabajador los cargos que se le imputan y a concederle un plazo razonable para que pueda ejercer su defensa o, si la causa estuviera relacionada con su capacidad, para que demuestre ésta o corrija su deficiencia. La única excepción se refiere, cuando la causa se relaciona con la conducta del trabajador, al caso de ufalta grave flagrante», que autoriza al empleador al despido inmediato, sin obligarlo a observar el procedimiento previo.

Obviamente, la existencia de este procedimiento anterior al acto del despido, directamente inspirado en el artículo 7 del Convenio 158 OIT y recogido por la LET, supone que, al menos en el criterio del empleador, el trabajador ha incurrido en algunas causas o faltas tipificadas por la ley, las cuales pone en su conocimiento para que levante los cargos. Si el empleador pudiera despedir sin necesidad de alegar causa justa, este procedimiento sería inútil.

Finalmente, el artículo 65, atendiendo al carácter recepticio del despido, impone al empleador la formalidad esencial de comunicar al trabajador su decisión de despedirlo, "mediante carta en la que se indique de modo preciso la causa del mismo y la fecha del cesen. Este mismo precepto, al inicio de su segundo párrafo, indica, en relación al probable reclamo judicial del trabajador contra el despido, que: «El empleador no podrá invocar posteriormente causa distinta de la imputada en la carta de despido", disposición que tiene por finalidad delimitar el debate judicial y la actividad probatoria, a la causa invocada por el empleador para justificar el despido.

El conjunto de estas normas nos indica, hasta el momento, que el TÚOLFE, en materia de despido, se afilia a la noción del despido causal, lo que, a sensu contrario, debería significar la invalidez de aquel despido cuya causa no es debidamente comprobada por el empleador en el proceso judicial que instaure el trabajador para impugnar su despido. Pero, además, debiera significar que todo despido que se produce sin siquiera imputar causa alguna, tendría que ser privado de todo efecto extintivo y sancionado con la nulidad.

Esta visión es, sin embargo, aparente, pues la propia ley (TÚOLFE) permite y tolera (¿quizá fomenta?) el despido incausado, tal como se deduce nítidamente del artículo 67 de la misma, que señala que: «Si el despido es arbitrario por no haberse expresado causa o no poderse demostrar ésta en juicio, el trabajador tiene derecho al pago de la indemnización $[\ldots] . »$ 
Conforme al artículo que acabamos de citar, la noción de "despido arbitrario" obedece a dos supuestos: a) despido sin expresión de causa, y b) despido con imputación de causa que no se demuestra en juicio. De ambos supuestos, sólo el segundo corresponde a un sistema legal que hace del despido causal el eje de su protección contra el despido injusto o arbitrario, pues el primero se encuadra, sin que quepa duda alguna, en la idea del despido libre, ad nutum o incausado, en que no se exige al empleador justificar el despido en una causa o falta determinada.

Así pues, la ilegitimidad del despido en el TÚOLFE se reduce a un concepto único, a un tipo exclusivo denominado "despido arbitrario", que engloba varias formas distintas, a saber : a) el despido de hecho, es decir, sin expresión de causa y sin comunicación al trabajador (sin procedimiento previo ni carta de despido); b) el despido debidamente notificado al trabajador, pero sin expresión de causa (sin procedimiento previo, pero con carta de despido que sólo señala fecha de cese), y c) el despido con procedimiento previo, imputación de cargos y carta de despido.

En otras palabras, bajo la expresión "despido arbitrario" se engloban formas diferentes de despedir, a las que se equipara respecto de su eficacia extintiva de la relación laboral y en la medida reparadora o sanción al empleador-según el ángulo desde el cual se prefiera mirar-que impone la ley. Ello quiere decir que, tan eficaz es el despido que prescinde de causa y forma, como aquel que observa ambas, aunque después no se demuestre la causa. En ambos casos, y también cuando se observe la forma (al menos por remitir la carta de despido) pero se omita expresar la causa, el despido será eficaz, produciendo la extinción de la relación laboral y el empleador será condenado a pagar una indemnización por despido arbitrario.

Desde un punto de vista práctico, para el empleador será más fácil y rápido despedir de hecho o -en todo caso-cursando una carta de despido sin expresión de causa, que tener que ceñirse a la alegación de causas y al procedimiento previo señalado por la ley; lo que, en buena cuenta, representa la restauración en nuestro sistema normativo laboral del despido libre, ad nutum, aunque pagado o resarcido mediante una indemnización.

\subsection{La tutela frente al despido arbitrario}

Una de las mayores novedades del TÚOLFE -y quizá la que constituya su propósito principal- es la profunda modificación que introduce en los mecanismos de tutela frente al despido, en sentido claramente peyorativo para el trabajador. 
Recordemos que bajo las leyes de estabilidad laboral ${ }^{17}$, vigentes sucesivamente desde 1970, la medida reparadora frente al despido injustificado o incausado era la reposición del trabajador en su anterior puesto de trabajo, en las mismas condiciones desempeñadas, con derecho a los aumentos salariales y mejoras producidas y al reintegro de las remuneraciones dejadas de percibir desde su despido. El pago de una indemnización, como medida reparadora, era una alternativa que, según las diversas leyes mencionadas, podía elegir el trabajador al impugnar judicialmente el despido o en ejecución de sentencia, una vez declarada la invalidez de aquél ${ }^{18}$.

El decreto legislativo 728, ley de Fomento del Empleo (LFE), mantuvo básicamente este sistema reparador, pero de acuerdo a su orientación desreguladora introdujo (art. 72) la posibilidad de que el juez pudiera sustituir, en la sentencia sobre la acción de reposición, esta medida reparadora por el pago de la indemnización por despido cuando la reposición "resultare inconveniente dadas las circunstancias". De este modo, la LFE abrió, por vez primera desde la década de los setenta, la posibilidad de sustituir la tutela restitutoria por la tutela resarcitoria en materia de despido, por voluntad ajena al trabajador, bien que dejando la decisión en manos del juez, lo que podía considerarse una garantía mínima.

La tutela restitutoria, plasmada en la reposición, obedece a la conexión lógica y jurídica entre ilegitimidad e ineficacia del despido, en razón de la cual la declaración judicial de ilegitimidad del despido conllevaba, como efecto necesario, la ineficacia del mismo, manteniendo la vigencia del vínculo laboral, debiendo por ello reponerse al trabajador en su puesto de trabajo.

El TÚOLFE consuma la tendencia desprotectora, esbozada en la LFE, y elimina como medida reparadora del despido "arbitrario" la reposición, dejando como única reparación posible la uindemnización por despido".

Lo señala así el ya citado artículo 67 del TÚOLFE y lo reitera, por si fuera necesario, el artículo 31 de su reglamento ${ }^{19}$ (RTÚOLFE), que señala: «Es arbitrario el despido que se produce en contravención del artí-

\footnotetext{
Los decretos leyes 18471 y 22126 , y la ley 24514.

En el régimen de los decretos leyes 18471 y 22126 , el trabajador despedido podía optar entre la acción de reposición y la acción indemnizatoria. La LET (ley 24514) estableció una acción única de impugnación o calificación del despido, que permitía al trabajador, en caso el despido fuera declarado injustificado, optar, en ejecución de sentencia, entre la reposición y la indemnización. La LFE restableció el sistema de dos acciones alternativas (reposición o indemnización).
}

19 Aprobado por el decreto supremo 001-96-TR, publicado el 26 de enero de 1996. 
culo 55 de la ley y se sanciona únicamente con la indemnización establecida en el artículo 71 de la misma.» El único supuesto de despido en que permanece como medida reparadora la reposición, es el despido nulo, al que nos referimos más adelante.

De esta suerte, el TÚOLFE ha reemplazado por completo la tutela restitutoria por la tutela resarcitoria del despido, lo que desde el punto de vista conceptual significa romper la conexión lógico-jurídica entre ilegitimidad-ineficacia del despido y admitir que el despido ilegítimo (incluso en los supuestos ya señalados del despido de hecho o sin expresión de causa) es, sin embargo, eficaz y sólo concede derecho a una compensación económica.

Por esta vía, la legislación laboral peruana retrocede a la figura del "despido pagado", es decir, a aquella situación en que corresponde al empleador un "poder" sólo limitado económicamente para despedir, sin que éste constituya una facultad excepcional que sólo se adquiere cuando el trabajador ha incurrido en una causa justa prevista por la ley. El que pueda, incluso, aproximarse esta figura a la del despido «libre», sin causa y sin cargas económicas, dependerá en mucho, como ya señalaba $\mathrm{Pla}$, del monto de la indemnización que deba pagarse al trabajador.

\subsection{La indemnización por despido arbitrario}

Convertida en la única medida reparadora del despido arbitrario, el interés se centra ahora en los alcances de la indemnización por despido establecida por la ley.

Como en las leyes de estabilidad laboral y en la LFE, la indemnización por despido es tasada, por lo que la determinación de su monto no depende ni de la pretensión del demandante ni del criterio del juez, sino de los criterios específicamente fijados por la ley.

Lo importante es destacar que en esta forma de tutela se ha producido una importante modificación, al haberse devaluado significativamente la aludida indemnización, como consecuencia de la derogación de la LET, que incluso durante la vigencia de la LFE seguía rigiendo para los trabajadores que gozaban del derecho a estabilidad laboral antes de la entrada en vigor de aquélla. El TÚOLFE rige ahora para todos los trabajadores que tenían vínculo laboral vigente al 29 de julio de 1995, razón por la cual frente a cualquier despido arbitrario que se produzca a partir de esa fecha los trabajadores sólo gozan de la protección prevista por esta norma, lo que implica que no tienen derecho a la reposición y que, adicionalmente, su derecho a la indemnización se ajusta a los montos que ésta señala. 
Si bien el TÚOLFE reproduce, con algunas variantes, la escala indemnizatoria establecida por el artículo $76 \mathrm{LFE}$, si se la compara con la prevista por la LET, la diferencia resulta notoria.

La LET estableció una escala de tres tramos: 3 remuneraciones mensuales para el trabajador con menos de un año de servicios, 6 para el que tuviera un año y menos de tres años, y 12 remuneraciones para el que tuviera tres o más años de servicios, hasta el límite de 12 remuneraciones mensuales. Además, el trabajador que optase por la terminación del contrato de trabajo tenía derecho al pago de las remuneraciones devengadas desde la fecha de interposición de la demanda, hasta la fecha de expedición de la resolución que ponía fin al proceso (LET, art. 14).

La escala fijada por la LFE contempló una indemnización equivalente a una remuneración mensual por año completo de servicios, más la fracción proporcional, con un mínimo de tres y un máximo de doce remuneraciones.

Aparentemente no hubo gran variación, porque el límite máximo es igual y un trabajador con más de doce años de servicios percibirá la misma indemnización; y en cuanto al límite mínimo, tampoco la habría para quien laboró menos de un año, porque en ambos sistemas su indemnización sería de tres remuneraciones. Pero la diferencia es notoria en los tramos intermedios: bajo la ley 24514 un trabajador con un año completo tendría derecho a 6 remuneraciones, pero sólo a 3 con la LFE; otro ejemplo: con la ley 24514 un trabajador con tres años completos percibiría 12 remuneraciones y sólo 3 con la LFE; finalmente, con la ley 24514 un trabajador con seis años de antigüedad cobraría 12 remuneraciones, pero únicamente 6 bajo la LFE.

Las variantes introducidas por el TÚOLFE reducen aún más la indemnización al eliminar el monto mínimo de tres remuneraciones, lo que significa que ahora el monto mínimo vendría a ser, en el caso de despedirse a un trabajador que cumplió el período de prueba y laboró un día más, 3 dozavos y un treintavo de su remuneración mensual. Una comparación completa puede verse en el cuadro de la página siguiente.

Como puede concluirse, la indemnización por despido -ahora la única medida reparadora de éste- ha sido devaluada, lo que asociado a la coetánea eliminación de la reposición, configura un cuadro de notoria desprotección frente al despido, que nos permite calificar al régimen que ahora tenemos como uno de "despido pagado barato".

Despido pagado «barato» que en no muy infrecuentes casos puede llegar a ser "gratuito", si pensamos en trabajadores con escasa antigüedad ( 4 o 5 años) y baja remuneración, a quienes el costo real de los litigios judiciales los desalentaría de optar por esa vía para exigir una 
indemnización que a la postre no van a disfrutar, ante lo cual el despido arbitrario quedaría sin reparación o sanción alguna.

Cabe reflexionar si estas situaciones, que no por hipotéticas carecen de realidad en nuestro medio, no nos colocan muy cerca del anacrónico sistema del despido libre, $y$, por el contrario, muy lejos de normas internacionales de reconocido prestigio y solvencia, como el Convenio 158 OIT, cuyo artículo 10 se refiere a una "indemnización adecuada» como reparación ante el despido injustificado.

Indemnización por despido

(remuneraciones mensuales)

\begin{tabular}{clll}
\hline $\begin{array}{c}\text { Años de } \\
\text { servicio }\end{array}$ & $L E T^{*}$ & $L F E$ & TÚOLFE \\
\hline+ de 3 mes. - de 1 año & $3 \mathrm{rem}$. & $3 \mathrm{rem}$. & $\begin{array}{l}\text { dozavos y } \\
\text { treintavos }\end{array}$ \\
\hline 1 año & $6 \mathrm{rem}$. & $3 \mathrm{rem}$. & $1 \mathrm{rem} .+\mathrm{frac}$. \\
\hline 2 años & $6 \mathrm{rem}$. & $3 \mathrm{rem}$. & $2 \mathrm{rem}$. \\
\hline 3 años & $12 \mathrm{rem}$. & $3 \mathrm{rem} .+\mathrm{frac}$. & $3 \mathrm{rem}$. \\
\hline 4 años & $12 \mathrm{rem}$. & $4 \mathrm{rem}$. & $4 \mathrm{rem}$. \\
\hline 5 años & $12 \mathrm{rem}$. & $5 \mathrm{rem}$. & $5 \mathrm{rem}$. \\
\hline 6 años & $12 \mathrm{rem}$. & $6 \mathrm{rem}$. & $6 \mathrm{rem}$. \\
\hline 7 años & $12 \mathrm{rem}$. & $7 \mathrm{rem}$. & $7 \mathrm{rem}$. \\
\hline 8 años & $12 \mathrm{rem}$. & $8 \mathrm{rem}$. & $8 \mathrm{rem}$. \\
\hline 9 años & $12 \mathrm{rem}$. & $9 \mathrm{rem}$. & $9 \mathrm{rem}$. \\
\hline 10 años & $12 \mathrm{rem}$. & $10 \mathrm{rem}$. & $10 \mathrm{rem}$. \\
\hline 11 años & $12 \mathrm{rem}$. & $11 \mathrm{rem}$. & $11 \mathrm{rem}$. \\
\hline 12 años & $12 \mathrm{rem}$. & $12 \mathrm{rem}$. & $12 \mathrm{rem}$. \\
\hline+ de 12 años & $12 \mathrm{rem}$. & $12 \mathrm{rem}$. & $12 \mathrm{rem}$. \\
\hline
\end{tabular}

* Más el pago de las remuneraciones devengadas. 


\section{El despido nulo}

\subsection{Su significación e importancia}

La noción del despido «nulo» fue introducida por la LFE, cuyo artículo 65 enumeró los motivos para calificar como tal el despido del trabajador. Dichos motivos son reproducidos mutatis mutandis del artículo 5 del Convenio 158 OIT, que señala que en ningún caso podrán constituir causa justificada para la terminación de la relación de trabajo.

$\mathrm{Al}$ considerarse ilícitos los motivos en que basa su decisión extintiva el empleador, el efecto de la declaración de nulidad del despido consiste en privar de toda eficacia a dicha decisión, que se considera inválida para extinguir la relación laboral, debiendo producirse, necesariamente, la reposición del trabajador. Precisando aún más, se afirma que: «[...] en tales casos la ineficacia o invalidez del acto de despido comporta que la relación de trabajo no se haya roto ni tampoco legítimamente interrumpido, y por tanto, es la misma relación de trabajo la que prosigue como tal. Con ello se priva al despido nulo del efecto resolutivo de la relación de trabajo ${ }^{20}$.

En el sistema de la LET, esta clase de despido no fue regulada, pero en verdad, desde el punto de vista de la tutela del trabajador ante el despido, ello no fue necesario porque esta ley privilegió la tutela restitutoria, razón por la que cualquiera que fuese el motivo real, o aparente, que tuviera el empleador para despedir, si no demostraba la existencia de la causa justa invocada el despido sería calificado como improcedente o infundado, con la consiguiente reposición del trabajador, salvo que optase por la indemnización.

En cambio, al abrir la LFE la posibilidad de que el juez sustituyera la reposición por la indemnización, a pesar de no haber acreditado el empleador la existencia de la causa invocada para despedir, la figura del despido nulo adquirió relieve, pues conforme a su artículo 71 la reparación de esta clase de despido es la reposición, sin que pueda el juez reemplazarla por el pago de una indemnización.

Bajo las normas del TÚOLFE, el despido nulo pasa a ser el único supuesto en que la ilegitimidad del despido se sanciona con su ineficacia, y como efecto necesario se produce la reposición del trabajador y el abo-

21) Monereo Pérez, José Luis, y Moreno Vida, María Nieves, “Forma y procedimientos del despido disciplinarion, en La reforma del estatuto de los trabajadores, tomo II, El Despido, AA.VV., dirigidos por Borrajo Dacruz, Efren, Editorial Revista de Derecho Privado/Editoriales de Derecho Reunidas, Madrid, 1994, p. 392. 
no de las remuneraciones dejadas de percibir desde que se produjo de hecho -aunque no de Derecho- la ruptura de su relación laboral.

\subsection{Los móviles del despido nulo}

El TÚOLFE únicamente considera como tales los que enumera, como ya se dijo, el artículo 5 del Convenio 158 OIT, que están referidos a despidos decretados por el empleador y que vulneran los derechos del trabajador a la libertad sindical, a recurrir a las autoridades competentes para la tutela de sus derechos laborales y a no ser discriminados en razón del sexo, raza, religión, opinión o idioma, o vulneran el derecho al trabajo de la mujer embarazada.

A diferencia de lo que sucede con el despido arbitrario, en el que "falta" la causa justa de despido, por no haberse demostrado en juicio la invocada por el empleador, en el despido nulo "existe" una causa, pero ésta es recusada por el ordenamiento jurídico, que la reputa ilícita por implicar la vulneración de derechos fundamentales que se reconocen al trabajador como tal y como persona y ciudadano.

Así tenemos que la libertad sindical está garantizada en el artículo 28, inciso 1, de la Constitución; el derecho a la no discriminación, en los artículos 2 inciso 2, y 26 inciso 1, de la misma Ley Fundamental; el derecho a la tutela jurisdiccional, en el artículo 139, y la protección a la madre trabajadora, en el artículo 23. Adicionalmente, y como norma de carácter general, es pertinente citar el tercer párrafo del artículo 23 constitucional, que señala que: «Ninguna relación laboral puede limitar el ejercicio de los derechos constitucionales, ni desconocer o rebajar la dignidad del trabajador.»

\subsection{La prueba del despido nulo}

La gran dificultad que presenta el despido nulo reside en el onus probandi, ya que se aplican reglas opuestas a las que rigen la prueba del despido arbitrario.

En efecto, el artículo 55 in fine del TÚOLFE impone al empleador la obligación de demostrar la causa invocada para el despido del trabajador, lo que significa que la actividad probatoria se desplaza por completo al empleador y que si éste no acredita la causa imputada como justificación del despido, éste será declarado arbitrario, sin que corresponda para ello al trabajador probar que no incurrió en las faltas alegadas. Se aplica aquí, analógicamente, la presunción de inocencia, propia del Derecho penal, pero extensible, en general, a todo sistema sancionador. 
En cambio, en el despido nulo la carga de la prueba se desplaza hacia el trabajador. Se deduce ello no sólo de la interpretación a sensu contrario del último párrafo del artículo 55 del TÚOLFE, sino del artículo $52 \mathrm{del}$ RTÚOLFE, que, para no dejar duda alguna al respecto, precisa que: «La acción de nulidad del despido requiere que cuando menos uno de los motivos a que se refiere el artículo 62 de la ley, sea expresamente invocado y acreditado por el trabajador como razón del mismo."

Con acertado criterio, observa Pasco que: «Acarrea dificultad práctica la demostración del despido nulo, ya que más que de causa habría que hablar de morivo, esto es, el resorte psicológico que genera la decisión de despedir. El motivo es siempre subjetivo y, por lo tanto, virtualmente indemostrable. ${ }^{21}$.

Como para confirmar este aserto, el RTÚOLFE ha introducido algunas tipificaciones en dos de los motivos enumerados por la LFE, que tornarán más ardua la tarea probatoria del accionante y la apreciación del juzgador. Así, el artículo 47 RTÚOLFE indica que cuando se trate del despido motivado por haber el trabajador presentado una queja o participado en un proceso contra el empleador, la queja o reclamo debe haberse presentado ante las autoridades administrativas o judiciales y además use acredita que está precedido de actitudes o conductas del empleador que evidencien el propósito de impedir arbitrariamente reclamos de sus trabajadores". Y si la discriminación constituye el móvil del despido, ésta debe entenderse como "[...] una notoria desigualdad no sustentada en razones objetivas o el trato marcadamente diferenciado entre varios trabajadores" (RTÚOLFE, art. 48).

Caracterizada, según lo que acabamos de ver, por su excepcionalidad y complejidad, la figura del despido nulo no modifica los rasgos definitorios del nuevo modelo normativo introducido por el TÚOLFE, que consagra el "despido libre pagado" ( $\mathrm{y}$ barato).

\section{El despido colectivo}

\subsection{Naturaleza y causas}

No altera el TÚOLFE la denominación de esta clase de despido, a la que persiste en llamar "cese colectivo", a pesar de que su verdadera naturaleza es la de un despido fundado en causas atribuibles a las vicisitudes

\footnotetext{
21 Pasco Cosmópolis, Mario, "La estabilidad laboral en la ley de Fomento al Empleo", en Análisis Laboral, n." 180, junio de 1992, p. 34.
} 
propias de la vida de la empresa y no a la conducta o capacidad del trabajador.

No se ha seguido en este campo el criterio adoptado por el legislador español al dictar la ley 11/1994, que modificó el Estatuto de los Trabajadores, y que a pesar de su talante flexibilizador, en el nuevo texto de su artículo 49, inciso 9, considera que el contrato de trabajo se extingue: "Por despido colectivo, fundado en causas económicas, técnicas, organizativas o de producción, siempre que aquél haya sido debidamente autorizado conforme a lo dispuesto en esta ley", sustituyendo la anterior expresión "cesación de la industria", en que se inspiró nuestra LFE ${ }^{22}$. Con ello, la ley española acoge el criterio ampliamente mayoritario de la doctrina y, sobre todo, acuña la terminología más apropiada para traducir la verdadera naturaleza de esta modalidad de extinción de la relación laboral.

El TÚOLFE sigue, en cambio, catalogando al "cese colectivo" como una causa de extinción del contrato de trabajo distinta al despido, lo que, entre otras cosas, plantea saber si el artículo 27 de la Constitución, que otorga al trabajador adecuada protección contra el «despido arbitrario", comprende en esa tutela al "cese colectivo", o si, en otras palabras, debemos llegar a la conclusión de que, conforme a la ley, no puede existir el cese colectivo "arbitrario".

En cuanto a las causas del cese colectivo, la novedad principal del TÚOLFE es la eliminación de las "necesidades de funcionamiento de la empresa" ${ }^{23}$, causa que motivó intensa discusión, tanto por su falta de definición ${ }^{24}$ como por la discrecionalidad que se concedió al empleador para despedir por esta causa, al margen del procedimiento del cese colectivo. Es una supresión conveniente, aunque sus efectos prácticos devengan disminuidos al haberse facilitado, en general, los mecanismos para el despido, lo que en el nuevo modelo la hubiera convertido en una causa casi innecesaria.

Se conserva, en cambio, como "causa objetiva" del cese colectivo, el supuesto de "disolución y liquidación de la empresa", proveniente de la

22 El texto sustituido decía: “Art. 49.- El contrato de trabajo se extinguirá: [...] 9. Por cesación de la industria, comercio o servicio de forma definitiva, fundada en causas tecnológicas o económicas, siempre que aquélla haya sido debidamente autorizada conforme a lo dispuesto en esta ley."

23 Prevista en el artículo 86, inciso d, de la LFE y regulada en sus artículos 90 a 92.

24 El Convenio 158 OIT asigna a la expresión "necesidades de funcionamiento" un sentido genérico que comprende como causas específicas a las económicas, tecnológicas, estructurales o análogas, pero no como una causa distinta e independiente de éstas, como, en cambio, lo hizo la LFE. 
voluntad societaria, que es una forma de despido colectivo ad nutum ${ }^{25}$. El cese por esta causa se exceptúa del procedimiento aplicable a los otros supuestos, como veremos más adelante.

\subsection{Las reformas al procedimiento de cese colectivo}

En una primera aproximación, la forma del despido colectivo podría catalogarse de continuista respecto a la normativa precedente porque mantiene la idea del "despido-propuesta", que inhibe al empleador de efectuar despidos colectivos directos, condicionando su facultad extintiva a la previa aprobación de la autoridad administrativa de trabajo, lo que, como se sabe, implica el ejercicio por ésta de un control ex ante, destinado a calificar las causas objetivas invocadas por el empleador.

No obstante, el procedimiento para la autorización del cese colectivo sufre importantes cambios, orientados a su simplificación y celeridad, que, como se verá, llegan a afectar las garantías mínimas de protección que dicho procedimiento, de por sí, implica.

\subsection{1}

Se conserva, como etapa inicial, la negociación directa entre el empleador y el sindicato -o, a falta de éste, entre aquél y los trabajadores afectados o sus representantes- destinada a acordar las condiciones del cese o las medidas que pudieran adoptarse para evitar o limitar dicho cese, otorgando al acuerdo a que se llegue fuerza vinculante (art. 82, inc. b, TÚOLFE).

Al proporcionar la empresa, al sindicato o los trabajadores afectados, la información sobre los motivos que invoca y la nómina de trabajadores afectados por el cese, que son requisitos para iniciar la negociación directa, dará cuenta al Ministerio de Trabajo para la apertura del expediente respectivo, eliminándose con esta comunicación la presentación de una solicitud que la LFE preveía como etapa posterior a la negociación y al dictamen de CONASEV o del Sector.

Demostrando, sin embargo, escasa confianza en la negociación -en cuyo caso resulta innecesaria la intervención de la Autoridad de Trabajo, sea porque el cese colectivo fue acordado por las partes o porque se evitó

\footnotetext{
25 Blancas Bustamante, Carlos, "Fomento del empleo y estabilidad laboral (II parte)", en Asesoria Laboral, Lima, febrero de 1992, p. 12.
} 
mediante la aplicación de medidas alternativas-, el TÚOLFE admite que en forma simultánea o sucesiva (en la LFE era una etapa necesariamente sucesiva) el empleador solicite a la CONASEV o al ministerio del sector, o, si el empleador no corresponde a un sector específico, a la Presidencia del Consejo de Ministros, el dictamen sobre la procedencia de la causa invocada, que constituye requisito indispensable para que la Autoridad de Trabajo se pronuncie sobre el cese colectivo. La simultaneidad de lo que antes eran fases sucesivas hace de la negociación directa un mero formulismo, sobre la cual el legislador evidencia su poca o nula convicción.

Otra novedad es que la norma indica que la inclusión, en la nómina de trabajadores afectados, de quienes están protegidos por el fuero sindical, «requiere justificación específica». Por lo pronto, el TÚOLFE zanja la duda existente respecto a si los trabajadores con fuero sindical podían ser incluidos en la nómina de cese colectivo cuando éste no comprendiera a la totalidad del personal de una empresa, en el sentido de que aunque el cese colectivo sea parcial, dichos trabajadores pueden ser cesados, exigiéndose, únicamente, "justificación específica». El RTÚOLFE indica que para la iniciación del expediente el empleador debe proporcionar a la Autoridad de Trabajo información relativa a la «justificación específica", si la nómina incluye trabajadores protegidos por el fuero sindical.

\section{2 .2}

Se faculta al empleador a presentar una pericia de parte al solicitar el dictamen de la CONASEV o del Sector sobre la procedencia de las causas invocadas, según el caso, la cual puede sustituir dicho dictamen oficial en el caso de que aquellos organismos no emitan su opinión en el plazo legal de quince días hábiles. En tal supuesto, la Autoridad de Trabajo resolverá sobre el cese colectivo en mérito a la pericia ofrecida por la propia parte que lo solicita, lo que, ciertamente, representa una ruptura de la igualdad procesal que debe existir entre las partes. El dictamen (si lo hubiere) y la pericia de parte serán remitidos por el empleador a la Autoridad de Trabajo, quien los pondrá en conocimiento de la parte laboral.

\section{2 .3}

También la conciliación se mantiene como fase del procedimiento, dentro del plazo perentorio de ocho días hábiles siguientes, pero como no- 
vedad se introduce otro mecanismo posible de solución del conflicto, al admitirse su sometimiento al arbitraje, por acuerdo de las partes, siempre que lo adopten dentro de los tres días hábiles siguientes al fracaso de la conciliación. El arbirraje previsto en el TÚOLFE (art. 82, inc. f) es voluntario y no potestativo, como el previsto en la ley de Relaciones Colectivas de Trabajo (LRCT), según se desprende de la referencia de los incisos $\mathrm{f}$ y g del artículo 82 TÚOLFE al acuerdo de partes.

Siendo así, parece difícil que el empleador que cuente a su favor con el dictamen de la CONASEV o del Sector, o a falta de éste, con su propia pericia de parte, tenga interés en sustraer el conflicto del ámbito de la Autoridad de Trabajo para someterlo al arbitraje, o que, en el caso inverso, es decir, si el dictamen de CONASEV o el Sector es contrario al cese colectivo, los trabajadores quieran hacerlo. Por ello, todo indica que la solución arbitral sólo tendrá carácter excepcional en esta clase de conflictos.

\section{2 .4}

Frustradas la negociación directa y la conciliación, y de no someterse el conflicto al arbitraje, corresponde resolver la procedencia del cese colectivo a la Autoridad de Trabajo, siguiendo un esquema que ha sido tradicional en nuestra normativa laboral.

Pero se produce aquí un cambio trascendente al introducirse la figura del silencio administrativo, que opera en sentido positivo en el caso de que la Autoridad de Trabajo no emita resolución «aprobando total o parcialmente la solicitud, o desaprobándola» (¿cuál solicitud?), dentro de los quince días siguientes al vencimiento del plazo para que las partes acuerden el arbitraje. La resolución, expresa o ficta, es apelable dentro de los tres días hábiles siguientes y en esta instancia el silencio positivo vuelve a operar si el recurso impugnatorio no es resuelto dentro del plazo de cinco (5) días hábiles, teniéndose por confirmada la resolución apelada.

La cuestión es relevante porque entraña una grave desnaturalización de la noción del silencio administrativo positivo, para privilegiar, alterando todo equilibrio, la posición del empleador. En efecto, el «silencio administrativo" se establece como un mecanismo destinado a proteger y favorecer al ciudadano en sus relaciones con la Administración del Estado, evitando que la omisión, inacción o falta de respuesta de ésta afecte los intereses o derechos de aquél, mediante la sanción de dicha inactividad con el pronunciamiento ficto de la autoridad administrativa. Cuando la ley considera que dicho silencio debe reputarse "negativo", lo que 
significa que el reclamo o petición debe entenderse denegado, el ciudadano queda legitimado para recurrir al Poder Judicial; pero cuando el silencio es reputado "positivo", el reclamo, solicitud o petición del interesado se entiende aprobado. Es un mecanismo destinado a democratizar el Estado y a acabar con el autoritarismo de la Administración, que muchas veces con el simple silencio postergaba o afectaba derechos y legítimos intereses ${ }^{26}$.

Pero se dan situaciones en las que la Administración interviene ope legis, en condición de ente "parajurisdiccional" o de ujurisdicción administrativa especial", que "[...] es aquella actividad administrativa de contenido jurisdiccional, por la que un órgano administrativo resuelve controversias entre simples particulares, de manera que la administración actúa en forma análoga a la de un juez» ${ }^{27}$. En esta actividad de la Administración, de operar el silencio administrativo positivo se favorecerá inevitablemente a la parte accionante, recurrente o solicitante, esto es, a aquella a la que correspondió la iniciativa del procedimiento, perjudicando, obviamente, a la otra parte, cuyos derechos o intereses se verán directamente afectados por una resolución ficta o presunta, $o$, lo que es lo mismo, por la inacción u omisión del ente administrativo. Puede decirse lo mismo cuando el silencio opera en sentido negativo, porque, en este caso, los derechos o intereses del accionante serían denegados, en favor de la parte contraria.

El silencio administrativo positivo aplicado para resolver o dirimir conflictos interpartes constituye, por consiguiente, una perversión de esta figura, porque habiendo sido concebido para tutelar al ciudadano frente a la Administración, se utiliza, en este caso, para amparar los derechos o intereses de un ciudadano en perjuicio de los derechos o intereses de otro. Semejante criterio implica la ruptura de la igualdad procesal de las partes porque sería una figura análoga a la de un proceso judicial en que el silencio del Juez implicaría, vencido el plazo para sentenciar, que se tenga por fundada la demanda, con lo que la dilación de los magistra-

\footnotetext{
26. En nuestra legislación administrativa el silencio posirivo se admite con ciertas restricciones: no se admite en el caso de los recursos impugnativos en que opera el silencio negativo (T.Ú.O. de la ley de Normas Generales de Procedimientos Administrativos, arts. 98 y 99), ni tampoco cuando pueda perjudicar gravemente los intereses del Estado o el interés público y en los procedimientos administrativos distintos a los conducentes al otorgamiento de licencias, autorizaciones, permisos, concesiones y similares, así como ciertos actos registrales, a que se refiere el artículo 27 del reglamento de la ley 25035, ley de Simplificación Administrativa, aprobado por el decreto supremo 070-89-PCM, modificado por el decreto supremo 002-90-PCM.

27 Drom1, José Roberto, Derecho subjetivo y responsabilidad puiblica, Editorial Themis Librería, Bogotá, 1980, p. 82 .
} 
dos tendría como beneficiarios a los demandantes en perjuicio de los demandados.

La introducción de esta figura en el procedimiento administrativo de cese colectivo lo desnaturaliza al privilegiar ostensiblemente la posición del empleador en desmedro del trabajador, pues de aqui en adelante bastará el silencio de la Autoridad de Trabajo para que el cese colectivo quede autorizado, lo que significa afectar, concretamente, los derechos del trabajador, sin que se cumpla la función que legitima la intervención de dicha autoridad en esta clase de despido: ejercer un control previo mediante la calificación de las causas invocadas por el empleador.

Ante semejante desregulación la pregunta que fluye es: ¿̨uál es el sentido de someter el cese colectivo a un control administrativo previo, si los instrumentos efectivos de ese control se han debilitado al punto de hacerlo inocuo?

\subsection{Excepciones al procedimiento de cese colectivo}

\section{3 .1}

El procedimiento anterior no es aplicable en su totalidad cuando la causa objetiva que legitima el cese colectivo es el caso fortuito o la fuerza mayor, que sean de tal gravedad que impliquen «la desaparición total o parcial del centro de trabajo" (art. 81 TUOLFE). En este caso se exonera al empleador de la presentación del dictamen oficial -o la pericia de parte sustitutoria- sobre la procedencia de las causas, y de la fase de conciliación, sustituyéndolas por la inspección que, con audiencia de partes, llevará a cabo el ministerio del Sector, la que se pondrá en conocimiento de la Autoridad de Trabajo para que emita resolución. Obviamente, tampoco cabe la opción del arbitraje, pues la ley no la menciona, pero entendemos que, en cambio, sí procede la negociación directa y el acuerdo de partes sobre el cese o su evitamiento gracias a medidas alternativas, pues no se suprime expresamente esta etapa del procedimiento.

\section{3 .2}

Finalmente, en los supuestos de disolución y liquidación de la empresa y la quiebra, el cese colectivo ya no se ajusta al procedimiento abreviado que regulaba la LFE, que eximía al empleador de la negociación directa y el dictamen oficial de CONASEV o del Sector, estableciéndose ahora, como única formalidad, cursar a los trabajadores el plazo de preaviso de 
cese de cinco días útiles a que se refiere la cuarta Disposición Complementaria del decreto ley $26116^{28}$, el cual podrá ser sustituido por el pago de la remuneración correspondiente, según lo establece el artículo 73 del RTÚOLFE. El preaviso ha sido reducido notoriamente, pues la LFE preveía para este supuesto el mismo plazo que para las demás causas, es decir, treinta días, salvo el caso fortuito o fuerza mayor.

Al carácter de despido colectivo ad nutum, que ya antes atribuimos al cese colectivo por disolución y liquidación de la empresa, acordada por la propia sociedad, se agrega su conversión en un despido directo, sujeto a la simple formalidad de un breve preaviso y sin pago de indemnización alguna.

28 Ley de Reestructuración Empresarial. 